\title{
Online Intellectual Virtues and the Extended Mind
} Lukas Schwengerer

\author{
Penultimate draft - please cite the published version!
}

https://www.tandfonline.com/doi/full/10.1080/02691728.2020.1815095

\begin{abstract}
The internet has become an ubiquitous epistemic source. However, it comes with several drawbacks. For instance, the world wide web seems to foster filter bubbles and echo chambers and includes search results that promote bias and spread misinformation. Richard Heersmink suggests online intellectual virtues to combat these epistemically detrimental effects. These are general epistemic virtues applied to the online environment based on our background knowledge of this online environment. I argue that these online intellectual virtues also demand a particular view of cognitive integration. Online intellectual virtues are incompatible with a popular conception of extended minds proposed by Andy Clark and David Chalmers . I suggest that if we want to hold on to both a conception of online intellectual virtues and some conception of the extended mind, we have to accept a more gradual theory of cognitive integration along the lines of second-wave theories of the extended mind.
\end{abstract}




\section{Introduction}

The Internet has become a pivotal epistemic source. We use it all the time, from looking up the weather in the morning, to finding routes to sights and finding out how long a particular cooked dish will likely last in the fridge without going bad. It is an easy way to acquire knowledge - a lot easier than trying without the Internet in most cases. For instance, try Michael Lynch's (2016, p. 21) experiment and find out without the Internet whether a four-stroke outboard engine is more effective than a two-stroke. The task is surprisingly difficult - at least if you do not just happen to have a mechanic in your family. If I am allowed to search the Internet I can find the answer in minutes. It is that easy.

The epistemic benefits of the Internet are vast, even though they come with drawbacks (Heersmink, 2016; Smart, Clowes, \& Heersmink, 2017). With all the true information on the Internet comes a lot of misinformation. Search results can present us with misinformation in such a prominent way that we accept them uncritically (Lynch, 2016) and they tend to promote biases and harm minorities through their algorithms (Noble, 2018). Moreover, the Internet seems to foster filter bubbles and echo chambers in social media via personal and filtered information (Simpson, 2012; Miller \& Record, 2013; Nguyen, 2018). Both Lynch (2016) and Noble (2018) provide concrete examples of Google Search results that are incorrect (e.g. creationist answers to 'what happened to the dinosaurs?' (Lynch, 2016, p. 66)) and foster stereotypes (e.g. mugshots when searching for pictures of 'three black teenagers' (Noble, 2018, p. 81))..$^{1}$ Moreover, even though Google's search algorithm is not public, Sullivan et al. (2020) tested a closely related PageRank calculation with a dataset based on Twitter and suggest that PageRank is not always a reliable indicator for truth. These drawbacks are significant and our use of the Internet has to adjust to these problems. Heersmink (2018) suggests intellectual virtues as a way out. He proposes that we need to cultivate character traits that help us in a responsible use of the

\footnotetext{
${ }^{1}$ Google continuously works on improving on these issues. However, some of these issues are still relatively easy to reproduce. While Google largely removed stereotypes from Google Search autocomplete in English it does not take much work to reproduce the issue in languages other than English. For instance, in August 2020 the German prompt 'warum sind Schwaben so...' leads to Google suggesting to complete this sentence with the German words for 'stingy', 'angry' and 'arrogant', indicating that a particular group of people has these attributes.
} 
Internet. I take this to be a promising approach. However, it comes with a downside if we combine online intellectual virtues with an independently successful research paradigm in the philosophy of mind: the extended mind. The extended mind was first proposed by Clark \& Chalmers (1998) to help us understand how our reliance on external artifacts shapes our cognitive processes and mental states. They argue that we should not accept a sharp divide between an individual's cognitive apparatus and external artifacts. Instead we should conceive of a person and the tools they use as a single system. The upshots are easier and more accurate descriptions and predictions of people and their artifacts.

Both online intellectual virtues and the extended mind thesis are independently supported. Online virtues seem to be a promising response to the downsides of the World Wide Web. The extended mind thesis seems to be a promising way to understand the human-artifact relationship. Ideally we want to work with both of these suggestions. However, I argue that we cannot rely on Clark \& Chalmers's conception of cognitive integration constituting an extended mind, if we want to find a place for intellectual virtues online. Clark \& Chalmers's proposal is too rigid to keep any space open for online intellectual virtues.

I start with a quick overview of Heersmink's (2018) idea of a virtue epistemology of the Internet in part 1. In part 2 I argue that Clark \& Chalmers's version gives us reason to think that the Internet cannot be part of our extended mind, if we want to be virtuous. I show this by focusing on Google Search. I suggest in part 3, that Heersmink's dimensions of integration allow that we can be both extended and virtuous and therefore his framework should be preferred.

\section{Epistemic Virtues and the Internet}

Virtue epistemology is a label for theories of knowledge that put the agent and its role in acquiring knowledge in the spotlight. To understand knowledge we need to understand what makes potential knowers good or bad thinkers. Agents are the primary object of epistemic evaluation (Battaly, 2008). Virtue epistemology comes in two forms: virtue reliabilism and virtue responsibilism. The former looks 
primarily at an agent's faculties and evaluates how these faculties relate to the truth of beliefs formed by the faculties (e.g. Sosa (2007), Greco (2009), Pritchard (2012)). The latter focuses on character traits - intellectual virtues and vices (e.g. Zagzebski (1996), Baehr (2015)). Heersmink subscribes to virtue responsibilism in his approach to the Internet, therefore I will limit myself to virtue responsibilism as well.

Heersmink's focus is on intellectual virtues as character traits that can be learned and improved. In line with Zagzebski (1996), Battaly (2008) and Baehr (2015) he is interested in what traits a virtuous epistemic agent should acquire. This focus is well motivated in response to the problems of the Internet. We are confronted with the practical question of how to deal with epistemic problems while retaining all the advantages of the Internet. Virtue epistemology suggests that we can do that, if we acquire the right character traits. These traits make us resistant to the problems and promote the epistemic benefits of the Internet. Virtues do not provide a guarantee for arriving at true beliefs, but they help us to believe responsibly and increase the likelihood of true beliefs. But what actual traits can fulfil this job description for the Internet?

For Heersmink online intellectual virtues are instances of general intellectual virtues, that are applied in an online environment based on relevant background knowledge of this environment. This conception is developed in two steps. First he provides a list of virtues by Baehr (2015) as a starting point: curiosity, intellectual autonomy, intellectual humility, attentiveness, intellectual carefulness, intellectual thoroughness, open-mindedness, intellectual courage, and intellectual tenacity. In the second step he discusses Internet literacy skills to illustrate intellectual virtues related to the Internet. For instance, Google ${ }^{2}$ uses personal information to inform its search result. Heersmink points out that this might limit the available body of information for an agent (referring to Simpson (2012) and Miller \& Record (2013)). Moreover, Google can be gamed. It is a particular specialisation in advertising to push a website towards the first search results on Google. The Search Engine Marketing Professional

\footnotetext{
${ }^{2}$ I use 'Google' to refer to Google Search.
} 
Organization (SEMPO), now part of the Digital Analytics Association (DAA), has as its only goal to provide research and resources on how to analyse data and game the new opportunities in the Internet for profit. Heersmink suggests that a virtuous user of the Internet will be aware of these influences on results in Google. Virtuous agents will mitigate the effects by using multiple search platforms, finding ways to turn off tracking tools, and look further than the top result of a search. These are behaviours that point to intellectual open-mindedness. It is an instance of looking for more sources to find alternative views that are worth considering.

Importantly, this behaviour is not merely an indication for open-mindedness. It is also a result of intellectual humility; of knowing the limitations of oneself as an agent in the online search environment. This points to a more general feature of online intellectual virtues that I want to emphasise. Online intellectual virtues are highly dependent on knowledge and understanding of the mechanisms at work on Internet sites. An agent needs to know how Google Search results are generated - or at least which factors influence these results. Otherwise their general open-mindedness will not be applicable. And neither can they be intellectually careful without knowing sources of error in Google. This is important when these online virtues are meant to be the solution to epistemic problems of the Internet. Intellectual virtues are the answer to a practical question of what to do when using the Internet as a source of knowledge. Intellectual virtues are supposed to solve epistemic problems of the Internet. We can now see that this requires at least some knowledge of how the Internet works. And given how quickly the mechanisms behind Internet sites change, this is difficult to achieve long-term. Hence, Heersmink encourages a life-long practice of improving Internet literacy (Heersmink, 2018, p. 10).

I have now sketched the idea of online intellectual virtues. I now explain how these virtues do not go well together with the idea of an extended mind along the lines of Clark \& Chalmers (1998). 


\section{Extended Mind and Online Virtues}

We use and manipulate our environment to help us with all sorts of tasks. We do math on paper, we write post-it notes to remember things, and we use small-scale model buildings when we plan a new apartment block. Humans are good at outsourcing cognitive work from their head into the environment. Clark \& Chalmers (1998) were the first to use these kinds of observations to argue that our cognitive processes and mental states might sometimes be best thought of as extended to the environment. Cognition and mentality should not be taken to be limited to our skull and brain. Cognitions leaks into our surroundings.

Theories to spell out this idea can be described in two waves (Heersmink, 2015). The first wave exemplified by Clark \& Chalmers's original extended mind paper in 1998 focuses on functional similarity between outside processes and processes in the head and takes the question of whether something is part of the extended mind to be answered in a binary fashion. Either something is part of the mind, or it is not. The second wave, exemplified by Sutton (2006) and most clearly formulated in Sutton (2010), stops focusing on the functional similarities, but looks for complementary functions found in the use of the environment. The extended mind idea becomes more gradual in this tradition. The focus is on different dimensions of cognitive integration that the environment might fulfil to different degrees. I will now address the first wave conception and show that it cannot be combined with online intellectual virtues, before presenting second wave theories as a solution to this challenge.

\section{First Wave - Binary Extendedness}

Clark \& Chalmers's (1998) strategy in arguing for the extended mind thesis is best illustrated with the example of Otto.

Otto suffers from Alzheimer's disease, and like many Alzheimer's patients, he relies on information in the environment to help structure his life. Otto carries a notebook around with him everywhere he goes. When he learns new information, he writes it down. When he needs some old information, he looks it up. For Otto, his notebook plays the role usually played by 
biological memory. Today, Otto hears about the exhibition at the Museum of Modern Art, and decides to go see it. He consults the notebook, which says that the museum is on 53rd Street, so he walks to $53^{\text {rd }}$ Street and goes into the museum. (Clark \& Chalmers, 1998, pp. 12-13)

Clark \& Chalmers ask us to look at the functional similarities between Otto and Inga, a person visiting the same museum who is not memory impaired. Inga clearly has a cognitive process going on that involves a dispositional belief. When we look at Otto and his notebook and consider them together as a single system they seem to behave just the same as Inga. The notebook plays the same functional role as Inga's biological memory. The notebook is with Otto to a similar extent as Inga's biological memory. Not always, but often enough. Otto usually does not question the content of the notebook. When he needs some information he just retrieves it from the notebook, just like Inga does from biological memory. It is difficult to find a functional difference between Inga and the combination of Otto and his notebook. And if we cannot find a functional difference, then we should treat them the same. That's the claim that Clark \& Chalmers are going for. If Inga's process is taken to be cognitive and mental, then what Otto and his notebook are doing should be accepted as cognitive and mental too. This step involves a commitment to the so-called parity principle:

If, as we confront some task, a part of the world functions as a process which, were it to go on in the head, we would have no hesitation in recognizing as part of the cognitive process, then that part of the world is (so we claim) part of the cognitive process (Clark \& Chalmers, 1998, p. 8).

If a process functions similar enough to something that we accept as cognitive if it were going on in the brain, then it should count as cognitive even if it happens in the external environment. So every time we use external tools to help us perform a task, we can ask whether these tools satisfy this principle. Could there be a similar enough process in the brain that we would classify as cognitive? If the answer is yes, then these external tools are part of a cognitive process too. If the answer is no, then it is not. There is no in-between. 
One might be worried here that this is too easy and too many external aids would qualify as part of the extended mind. However, Clark \& Chalmers underline that the similarity has to be close enough. Not any notebook counts as part of an extended mind. Otto's only counts because it functions like our storage of dispositional beliefs in memory. But perhaps this functional similarity is overstated. Opponents of the extended mind thesis heavily emphasise that even in the toy example that Clark \& Chalmers present the notebook and Inga's memory are importantly different. For instance, the use of notebooks can fail in different ways than our biological memory (cf. Rupert (2004), Sterelny (2004)), introspection might work differently with externally stored information (Gertler, 2007), biological memory is more in flux than content written into a notebook (Sutton, 2010) and perhaps there are differences in the nature of the content (Adams \& Aizawa, 2010). Some of these differences lead towards rejection of the extended mind idea altogether. I will not discuss these here. I presuppose for the purpose of this paper that some sort of extended cognition exists. Instead, I now point to a difficulty combining the idea with online virtues.

\section{Binary Extendedness and Online Virtues}

Let me start with a fictional example of an Internet source that satisfies Clark \& Chalmer's conditions for the extended mind.

Gotto, a memory impaired man, works in a museum and regularly talks with other people about historical events. Because of his bad biological memory, Gotto uses the Internet to get relevant information when he needs it. He uses his smartphone that he almost always carries with him to search on Google for the relevant events, retrieves information from the first websites he finds and uses that information immediately in conversation.

Gotto and the World Wide Web through his smartphone satisfy all relevant conditions. Gotto plus his smartphone with Internet access are functionally similar to a person with great historical knowledge. If a person would recall the relevant historical events and facts in their brain we would surely count this as part of cognition. Gotto and his Internet access behaves in some sense just like someone with 
extensive knowledge would. He has the smartphone almost always with him, just like biological (dispositional) beliefs are with us. He has the historical information readily available, whenever a relevant event comes up he looks it up and finds it, just like dispositional beliefs become active when needed. And he usually does not question the content, just like we usually do not question beliefs that become occurrent.

One might object here that there is a further condition for beliefs that is not satisfied here. Clark \& Chalmers $(1998$, p. 17) mention that beliefs have to be there because they were consciously endorsed at some point. However, they themselves find this condition questionable. There seems to be little reason to require that beliefs must be tied to conscious processes of endorsing a proposition. Clark \& Chalmers already raise counterexamples: perhaps subliminal perception or memory tampering can create beliefs without any conscious endorsement. Hence, Clark drops this fourth condition in future work (e.g. Clark (2010)). Gotto therefore seems to be a case of the extended mind in which the World Wide Web is part of the extension.

However, Gotto cannot be intellectually virtuous with regard to the Web. Crucially, for information provided by a tool to be part of my extended mind it has to be automatically endorsed. This is already present in the earliest formulation of the conditions for the extended mind, and continually repeated by Clark. For instance, he thinks that information retrieved has to be "[...] more or less automatically endorsed. It should not usually be subject to critical scrutiny (unlike the opinions of other people, for example). It should be deemed about as trustworthy as something retrieved clearly from biological memory" (Clark, 2010, p. 46). For Gotto's mind to include the Web he has to deem it as trustworthy as any ordinary human would treat standing beliefs stored in their brain. This is satisfied in Gotto's case. He indeed trusts the information he receives through a Google search highly. However, that stands in a clear conflict with how an intellectually virtuous agent ought to interact with Google Search. Online virtues demand a critical eye on information on the Web! 
Recall that online intellectual virtues are instances of general intellectual virtues, that are applied in an online environment based on relevant background knowledge of this environment. Gotto fails in this regard. He does not apply all relevant intellectual virtues in his use of Google and his acceptance of the information he finds. He does not satisfy intellectual autonomy. His inquiry is not independent of others in any shape or form. He does not think for himself. Intellectual autonomy does not require that a person cannot take any information from outside, but it requires that the information is evaluated by the person. It requires a sensitivity for recognising problems in a source - unreliability or dishonesty, for instance. A person that lacks intellectual autonomy does not make an attempt to independently judge whether information is correct. This goes hand in hand with intellectual carefulness. Virtuous epistemic agents avoid intellectual errors by employing methods that allow them to recognise potential problems in sources. They do not automatically endorse information. Both autonomy and carefulness require that evidence is not always taken at face value. They require some amount of distrust towards a potential source of knowledge and towards oneself as the potential receiver of evidence. Neither should be accepted automatically. In particular an intellectual virtuous agent using the Internet will not take Google results at face value. They will keep the conditions of the search results in mind and evaluate which result deserves to be trusted by themselves. Moreover, they will not merely take the first result but be open-minded to other results that are not ranked as highly.

All of these behaviours are in conflict with Gotto's attitude towards Google: he takes the information automatically as correct and endorses it without any critical thought. He just picks the first result without any hesitation. After all, for the artifact to count as part of his mind "[i]t should not usually be subject to critical scrutiny [...]" (Clark, 2010, p. 46). But a virtuous user of the Internet should usually critically scrutinize the information they find. They ought to apply intellectual autonomy, carefulness and open-mindedness to the platform in a way that counteracts epistemically detrimental effects of Google's algorithms. That is precisely what online virtues amount to. If I cannot apply my general intellectual virtues to the Web whenever the Web is part of my extended mind, then I cannot have both online virtues and a mind extended to the Web. I have to choose one or the other. 
Perhaps this is a little quick. One might be worried here that I neglect that the Web being part of my extended mind makes a difference in how intellectual virtues ought to be applied. I would not require an intellectually virtuous person to be so vigilant about beliefs stored in their memory. And if by the parity principle information stored online is functionally the same and should be treated the same, why do I still require this kind of scrutiny for the World Wide Web? They might pose this as a dilemma: either I accept that I can be virtuous and trust Web sources that are part of my extended self, or I demand that intellectually virtuous people show the same scrutiny for stored biological beliefs.

I reject this dilemma altogether and choose neither horn. Instead, I suggest that there are differences in belief generation that this comparison neglects. Frequency and ease of particular forms of belief generation depend on the architecture of brain and artifacts. Take Otto and his notebook. It is relatively easy to write new information into Otto's notebook and thereby generate a new dispositional belief. If I write that a new Greek restaurant is at $27^{\text {th }}$ street and Otto has the desire to eat Greek food he likely will look for Greek restaurants in his notebook and find the information I added. He then goes to $27^{\text {th }}$ street and finds a restaurant if my information was correct. And he will not suspect that I have planted a belief into his extended mind. However, it is comparatively difficult to generate new beliefs in other people without their awareness in a non-extended case. It is not ruled out, but I cannot write a belief into a brain in a couple seconds. It takes work.

This difference is important for how an intellectually virtuous agent ought to act. In case of the World Wide Web it is relatively easy to create or manipulate websites and search algorithms (cf. Clowes (2013), Heersmink (2018), Noble (2018)). Hence, a virtuous agent ought to be more vigilant than they need to be with regard to biologically stored beliefs. A virtuous believer cannot neglect the difference in how beliefs are usually formed in a cognitive system, because the difference matters for the proper application of intellectual virtues. An intellectually careful agent is aware of possible errors and mistakes in their particular situation. In some - but not all - cases the situation requires more scrutiny, more care, and more autonomy of the virtuous believer. Hence, a person that shows online virtues will not endorse content on the Web automatically and therefore not have a mind extended to the Web. 
This result is problematic, because it does not seem to fit with our experience interacting with the Internet. Neither option seems right. Discounting the Internet from being part of our cognitive processes fails to capture how pervasive the Internet is and how much we rely on it. But accepting some Internet uses as part of the extended mind also does not seem correct, because we are using it - at least sometimes - in a virtuous way. We need both, so we cannot rest with the first wave extended mind thesis.

\section{Grades of Extendedness and Online Virtues}

I have argued that the first wave extended mind account introduced by Clark \& Chalmers (1998) is incompatible with agents that are both extended and virtuous. I now suggest that second wave approaches in the extended mind debate fare better.

\section{Second Wave - Grades of Extendedness}

Thinkers in the second wave of cognitive extension approach the topic by considering how tools can help us do things we would not be able to do otherwise. We do not need a tool to help us perform basic math. I can calculate $2+2$ in my head. But we need tools when the numbers get higher and the mathematical operations more complicated. Most of us are rather limited in doing mental arithmetic. But give us a pen and paper and suddenly we can do a lot more. Give us a modern calculator and the mathematical world is our oyster. Tools enhance our capabilities and range of action. What we should be interested in are tools that provide us with new capabilities and are integrated into our cognitive processes. Clark himself puts forward this emphasis in joint work with Robert Wilson when they point to "hybrid processes in which the inner and the outer contributions are typically highly distinct in nature, yet deeply integrated and complementary" (Wilson \& Clark, 2009).

The motivation to look into complementary functions of artifacts has been developed among others by Sutton (2006), Menary (2010), and Heersmink (2015). They all have an aim in analysing artifacts according to different dimensions of cognitive integration. Parts of the environment can be more or less integrated on these dimensions, and therefore be overall more or less part of one's cognition. An 
artifact is not either part of the mind, or not, but instead it is integrated in a person's cognition to some degree on different dimensions. The resulting system is more complex and provides a more finegrained way of analysing artifacts and their use. This also makes the theory better equipped to deal with arguments raised against Clark \& Chalmers. For instance, these theories can deal with the objection that too much turns out to be part of the mind by pointing out that they do not claim that a particular object is fully part of the mind. Instead they merely talk about an object being cognitively integrated to some degree. That a lot of objects are integrated to some degree is more palatable than a binary extended mind thesis (Heersmink, 2015, p. 582).

Let me take a look at these dimensions in the refined version by Heersmink (2015).

Information Flow - the directions that information is passed on between an agent and an artifact.

Reliability - the frequency an artifact is used to impact the agent's cognitive processes.

Durability - the permanence of one's relation to an artifact.

Trust - the degree to which one takes the information provided by an artifact to be correct.

Procedural Transparency - the degree of fluency and effortlessness in interacting with an artifact.

Informational Transparency - the degree of fluency in receiving, interpreting and understanding information from the artifact.

Individualisation - the degree to which an artifact is personalized or can be used by anyone.

Transformation - the degree to which the cognitive capacities of an agent change in virtue of using an artifact. 
These dimensions allow for a fine-grained analysis of agent-artifact combinations. Consider Clark \& Chalmers's Otto case:

Otto and his notebook have a two-way informational flow that is very frequent. Otto looks up and writes in information all the time. It is a repeated interaction. He highly trusts the notebook - at least as highly as we ordinarily trust our memory! The notebook has good procedural and informational transparency. Otto does not have problems having the notebook on him continually and it is rather easy to read the notebook and retrieve information when necessary. How the notebook ranks on personalisation is unclear. On one hand, it is not especially individualized, because anyone can write into the notebook and read the contents. But on the other hand the contents are all written in by Otto and for Otto - that looks very personal. The exact amount of personalisation depends on how we would flesh out the case further. Perhaps he modified the notebook slightly for his purpose, or perhaps he writes down his notes in a particular style or handwriting that is not easily accessible for others. In these cases the notebook ranks high on personalisation. It is also not clear how Otto's notebook ranks on the transformation category. It certainly changes Otto's cognitive capacities compared to Otto without a notebook. Less so compared to Otto before Alzheimer's disease. Overall Otto and his notebook rank highly in all these categories. That is not surprising, given that the Otto case is meant to satisfy a more binary criterion for the extended mind. We should expect the case to also count as one with the notebook being cognitively integrated to a high degree in Heersmink's account.

However, my personal notebook is less cognitively integrated than Otto's. I only use it to write down especially important appointments, and I do not have it with me all the time. It might still rank highly on the trust criterion, but less so on procedural transparency and reliability. Clark \& Chalmers have to claim that my notebook is not part of my extended mind. Heersmink can make a more fine-grained judgment and describe my notebook as integrated to some extent, but way less than Otto's notebook. Heersmink does not provide any threshold for something to count as integrated enough to be part of an extended mind. We should rather think of an artifact as more or less part of my mind, depending 
on the integration. A lot of artifacts might count as part of my mind to a miniscule degree, but only few will be highly integrated.

\section{Grades of Extendedness and Online Virtues}

Grades of extendedness are more promising for a combination with online virtues. While the application of intellectual virtues to the online world might give us restrictions on some dimensions, it has little impact on others. Hence, there might be room for combinations of agents and artifacts that still count as showing an overall high degree of cognitive integration, while being virtuous epistemic agents. Let me illustrate this with a variation of the Gotto case:

Sgotto, a memory impaired man, works in a museum and regularly talks with other people about historical events. Because of his bad biological memory, Sgotto uses the Internet to get relevant information when he needs it. He uses his smartphone that he almost always carries with him to search on Google for the relevant events, looks through the results carefully and retrieves information from the websites he takes to be the most promising. He then uses that information in conversation, but the whole process takes a while.

Sgotto is a virtuous agent. He considers multiple entries in the search results and evaluates them carefully. He does not automatically endorse any website. This comes at the cost of speed. Sgotto and the Web do not qualify as making up an extended mind under the conditions of Clark \& Chalmers. He lacks the automatic endorsement required. However, Sgotto might still count as a person who has the Web cognitively integrated to some degree, given that Heersmink \& Sutton (2020, p. 157) rank common uses of Google Search as medium to highly integrated. Sgotto is a little more careful, but nevertheless ranks similarly. For instance, the system is high on the reliability scale, because he frequently uses the Web to retrieve information. Moreover, the system shows a (mostly) one-way information flow that is repeatedly used over a long time. It is to some degree individualized depending on how much personalization Google works with. And it is also somewhat transformative, because it allows Sgotto to engage in activities he could not do otherwise. Likely this also comes with 
some changes on the cognitive architecture of Sgotto (although this is speculative). These all speak already in favour of higher cognitive integration. However, procedural transparency, informational transparency and trust do point in a different direction.

Let me start with the trust dimension. Sgotto looks at search results, considers these carefully and then retrieves information from a website he takes to be most promising. He trusts the website only after judging how good of a source it is. Carefully looking through search results is anything but having a trusting attitude. That is essential for a virtuous user of the Internet. Sgotto needs to be intellectually careful. He compares short descriptions - blurbs - of websites in Google to each other and to his own beliefs. Only those that seem to be a reasonable fit with his beliefs deserve a visit. Therefore, Sgotto ranks low on the trust dimension. Otto automatically accepted what was written in his notebook. Gotto accepted the first result in Google without question. Sgotto looks carefully and judges whether and which website he takes to be correct.

Procedural transparency captures the effort and conscious attention required to deploy an artifact. In Sgotto's case this also is only satisfied to a low degree. It is easy for Sgotto to start Google and search. However, the evaluative practice necessary to carefully look through the results and pick the most promising website requires effort - and perhaps even conscious attention. It is not easy to judge whether a website is a good source. Sgotto has to heuristically evaluate what links to click based on their descriptions, the domain, the ranking in Google, and coherence with his own beliefs. And when he visits a site he has to quickly decide whether the site is useful for his purpose. He might consider not only the content, but the design and presentation on the site. An experienced user will notice contextual cues on a website that indicate how much time and effort was spent on a site and use these factors to infer how much time was likely spent to curate and fact-check the content. These heuristics will not guarantee truth, but they can be a necessary shortcut to handle the vast amount of sites on the World Wide Web. But it all takes effort, even for experienced Internet users. Hence, Sgotto cannot rank highly on procedural transparency if he wants to remain virtuous. 
Some of the aspects impeding procedural transparency are also part of informational transparency, which captures the effort of interpreting and understanding information. In the online world procedural and informational transparency have no sharp divide. Deploying Google requires interpreting and understanding information. Google works by and large with language and requires competent interpretation and understanding of language. Informational transparency depends mostly on how well and quickly these linguistic components of Google are processed and lead to understanding of approximate website contents. When Sgotto carefully evaluates Google results he reads and understands the website descriptions and makes an inference to the expected website contents. Moreover, he also requires some information about the logic behind the search results how they are generated. His use of Google is only successful if he gets the expected epistemic value from websites reliably right. He needs to understand websites and Google's ranking well enough before clicking on any site, otherwise his use of Google is ineffective and cannot lead to relevant true information. Generally, as long as he is aiming for true beliefs about the subject matter he will not rank very highly on this dimension. His understanding of mere website blurbs might be quick, but because he needs understanding over and above blurbs he needs inferences that require more effort and time. A carefully evaluating Sgotto therefore cannot be at the top-end of informational transparency. Moreover, even less careful users still do not rank highly on informational transparency because the algorithms generating search results are not transparent, whereas they could rank higher on procedural transparency and trust than cautious Sgotto (cf. Heersmink \& Sutton (2020, p. 157)).

In this case trust and transparency go hand in hand. Because Sgotto ranks low on the trust dimension he also is not well-integrated according to transparency. And Sgotto ranks low on trust because he is intellectually virtuous. Online intellectual virtues are instances of general intellectual virtues, that are applied in an online environment based on relevant background knowledge of this environment. And in this case, intellectual carefulness and attentiveness requires an attitude that is non-trusting. It requires that Sgotto evaluates search results and judges their quality based on his knowledge of Google and features that indicate correct and valuable content on websites. This is an effortful procedure that 
cannot come with automatic endorsement. If we follow Clark (2010, p. 46) and understand automatic endorsement as deeming something "[...] as trustworthy as something retrieved clearly from biological memory" (Clark, 2010, p. 46), then Sgotto cannot trust automatically. He needs to judge carefully whether to trust. Because the intellectually careful cannot trust automatically, they cannot be both virtuous and integrate the Web to the fullest extent. Nevertheless, Heersmink's dimensions allow us to capture how artifacts can be cognitively well-integrated in some respect. One can be both intellectually virtuous and integrate the Web on non-trust and non-transparency dimensions to a high degree. ${ }^{3}$ This is exactly what we wanted in order to capture a virtuous relation to Google Search. Hence, we found at least one Internet-based application that we can conceptualise properly as cognitively integrated with Heersmink, but not with Clark \& Chalmers (1998). Their approach would lose either cognitive integration of this particular use of the Internet, or virtuous epistemic interaction. Heersmink can get us both and therefore provides the right framework to work with.

\section{Conclusion}

I have shown that online intellectual virtues are incompatible with Clark \& Chalmers (1998) original way of thinking about the extended mind. Their binary notion of extendedness forces us in the case of Google Search to choose between vicious, extended beliefs and virtuous, non-extended beliefs. Online intellectual virtues require that we do not trust automatically, but rather evaluate websites and search results - for instance according to our best knowledge of the mechanisms producing search results. Because the original extended mind idea is an all-or-nothing concept we are therefore stuck denying that virtuous users can be extended to the Internet as used in Google Search. Heersmink's dimensions of cognitive integrations give us a conceptual way to describe an extended mind without automatic trust. We can accept cognitive integration on some dimensions without requiring integration on all of them. A virtuous user has reliable, durable information flow that transforms cognitive operations and can be individualised. Nevertheless, it is not automatically trusted and cannot rank very high on

\footnotetext{
${ }^{3}$ Perhaps it is even possible to rank high on every dimension besides trust. I do not have space to discuss such a case.
} 
transparency. In this way Heersmink's framework allows us to capture how integration does not necessarily entail that we have to abandon online intellectual virtues. Whether that possibility is something that one can achieve in practice is up for future research. Certainly, the mere existence of online intellectual virtues is no carte blanche for corporations to burden users with all the epistemic work.

\section{Acknowledgments}

Thank you to two anonymous reviewers for their helpful comments and recommendations improving this paper.

\section{References}

Adams, F. R., and Aizawa, K. 2010. Defending the bounds of cognition. In The Extended Mind, edited by R. Menary, 67-80. Cambridge, MA: MIT Press.

Baehr, J. 2015. Cultivating Good Minds: A Philosophical and Practical Guide to Educating for Intellectual Virtues. Retrieved from https://intellectualvirtues.org/why-should-we-educate-forintellectual-virtues-2-2/

Battaly, H. 2008. "Virtue Epistemology." Philosophy Compass, 3(4): 639-663.

Clark, A. 2010. Memento's Revenge: The Extended Mind, Extended. In The Extended Mind, edited by R. Menary, 43-66. Cambridge, MA: MIT Press.

Clark, A., and Chalmers, D. J. 1998. "The extended mind." Analysis, 58(1): 7-19.

Clowes, R. 2013. "The Cognitive Integration of E-Memory." Review of Philosophy and Psychology, 4(1): 107-133.

Gertler, B. 2007. Overextending the mind? In Arguing About the Mind, edited by B. Gertler, \& L. Shapiro, 192-206. New York: Routledge. 
Greco, J. 2009. “Knowledge and Success From Ability." Philosophical Studies, 142(1): 17-26.

Heersmink, R. 2015. "Dimensions of Integration in Embedded and Extended Cognitive Systems." Phenomenology and the Cognitive Sciences, 13(3): 577-598.

Heersmink, R. 2016. "The Internet, Cognitive Enhancement, and the Values of Cognition." Minds \& Machines, 26(4): 389-407.

Heersmink, R. 2018. "A Virtue Epistemology of the Internet: Search Engines, Intellectual." Social Epistemology, 32(1): 1-12.

Heersmink, R., and Sutton, J. 2020. “Cognition and the Web: Extended, Transactive, or Scaffolded?" Erkenntnis(85): 139-164.

Lynch, M. 2016. The Internet of Us: Knowing More and Understanding Less in the Age of Big Data. New York: W.W. Norton and Company.

Menary, R. 2010. “Dimensions of Mind." Phenomenology and the Cognitive Sciences, 9(4): 561-578.

Miller, B., and Record, I. 2013. "Justified Belief in a Digital Age: One the Epistemic Implications of Secret Internet Technologies." Episteme, 10(2): 117-134.

Nguyen, T. C. 2018. “Echo Chambers and Epistemic Bubbles." Episteme, 17(2): 141-161.

Noble, S. U. 2018. Algorithms of Oppression. New York: New York University Press.

Pritchard, D. 2012. “Anti-Luck Virtue Epistemology." Journal of Philosophy, 109(3): 247-279.

Rupert, R. 2004. "Challenges to the Hypothesis of Extended Cognition." Journal of Philosophy 101 (8): 389-428.

Simpson, T. W. 2012. "Evaluating Google as an Epistemic Tool." Metaphilosophy, 43(4): 426-445.

Smart, P., Clowes, R., and Heersmink, R. 2017. "Minds Online: The Interface between Web Science, Cognitive Science, and the Philosophy of Mind." Foundations and Trends in Web Science, 6(12): 1-234. 
Sosa, E. 2007. A Virtue Epistemology: Apt Belief and Reflective Knowledge (Vol. 1). Oxford: OUP

Sterelny, K. 2004. "Externalism, Epistemic Artefacts and the Extended Mind." In The Externalist Challenge, edited by R. Schantz, 239-254. Berlin: De Gruyter.

Sullivan, E., Sondag, M., Rutter, I., Meulemans, W., Cunningham, S., Speckmann, B., \& Alfano, M. 2020. "Can Real Social Epistemic Networks Deliver the Wisdom of Crowds?" In Oxford Studies in Experimental Philosophy (Vol. 3), edited by T. Lombrozo, J. Knobe, and S. Nichols. Oxford: OUP.

Sutton, J. 2006. "Distributed cognitions:domains and dimensions." Pragmatics and Cognition, 14(2): 235-247.

Sutton, J. 2010. "Exograms and interdisciplinaryity: History, the extended mind and the civilizing process". In The Extended Mind, edited by R. Menary, 189-225. Cambridge: MIT Press.

Wilson, R. A., and Clark, A. 2009. "How to situate cognition: Letting nature take its course." In The Cambridge Handbook of Situated Cognition, edited by M. Aydede, and P. Robbins, 55-77. New York: Cambridge University Press.

Zagzebski, L. 1996. Virtues of the Mind: An Inquiry into the Nature of Virtue and the Ethical Foundations of Knowledge. Cambridge: Cambridge University Press. 